\title{
Tracking trends in Canadian gastroenterology research
}

\author{
Diane Finegood $\mathrm{PhD}^{1}$, Paul C Adams MD², Editor-in-Chief
}

$\mathrm{D}_{\mathrm{l}}^{\mathrm{t}}$ Diane Finegood is the Scientific Director of the Canadian Institutes of Health Research (CIHR) - Institute of Nutrition, Metabolism and Diabetes (INMD). The institute supports research directed at enhancing health in relation to diet, digestion, excretion and metabolism; and includes research relevant to a wide range of conditions and problems associated with the digestive system, kidney and liver function, and hormones.

PA: Over the past years, many gastroenterologists and scientists have, unsuccessfully, tried to create a CIHR Institute for Digestive Diseases. Presently, many of our research projects are under the umbrella of the CIHR - INMD and as a result, many gastroenterology researchers feel at a disadvantage compared with other specialties with their own institute.

DF: There were a large number of groups who petitioned for their own institute and there are many ways to divide up responsibilities among institutes. My own sense is that the architects of the CIHR found the right balance between the number of institutes and the type of focus. I tend to place the institutes in three categories: disease and body part institutes (eg, the INMD, the Institute of Circulatory and Respiratory Health and the Institute of Cancer Research), vulnerable population institutes (eg, the Institute of Aboriginal People's Health and the Institute of Aging) and types of research institutes (eg, the Institute of Genetics and the Institute of Population and Public Health). This mix has brought together a diverse group of scientific directors to help shape the directions of the CIHR. It also means that many researchers will be interested in an affiliation with multiple institutes and the institutes must work together to develop initiatives.

Funding for gastrointestinal (GI) and liver research at CIHR has grown at the same pace as the CIHR's grants and awards budget (1.9-fold) since fiscal year 2000/2001 (Figure 1). Approximately one-half of the liver research grants were for hepatitis-related projects.

The funding channelled through each institute is a relatively small portion (approximately 1\%) of the CIHR grants and awards budget and is intended for strategic initiatives. The INMD's initiatives are motivated by our strategic plan, which articulates our focus on obesity and strategic partnerships across our mandate. The INMD supports GI training through the Strategic Training Initiative in Health Research and University Industry programs. We support workshops like the Research Topics in Gastrointestinal Disease series and we welcome new opportunities to develop strategic partnerships with the GI research community. GI researchers can also benefit from our travel grant program, which supports trainees and new investigators in all areas of the INMD's broad mandate.

PA: This problem also occurs at the review level where many GI grants are reviewed under the Experimental Medicine (EM) panel, which is a broad collection of scientists with no particular expertise in digestive diseases.

DF: GI grants are reviewed by a wide range of the CIHR peer review panels (Figure 2). Only one-third of GI grants were reviewed by the EM panel from 2000 to 2006. Many other committees reviewed significant numbers of GI grants including Microbiology \& Immunology, Pharmacology \& Toxicology, and Metabolism. Given the larger number of GI grants reviewed by the EM panel, reviewers with expertise in digestive diseases are recruited to this panel and are used as external reviewers.

The perception that GI researchers are at a disadvantage when considered by the EM panel is not supported by an analysis of success rates (Figure 3). The percentage of grants funded from specific areas varies from competition to competition; for example, in some competitions the GI researchers have done better than the kidney researchers or the overall panel, and in other years they have done worse. This variation is likely due to many factors including the relatively small number of grants in each area, the quality of the grants in the competition and the willingness of GI researchers to sit on the panel.

The CIHR's recent international review panel stated that "the panel system that is responsible for handling most of the research funding is currently under strain. It requires more academic leadership, and a review of process and structure for this system is necessary" (1). The subcommittee on Monitoring and Innovation in Peer Review (2) has started discussing options for restructuring the panel system and a moratorium has been put on the creation of new panels.

PA: There is an impression that basic research is declining within the Canadian GI field, particularly among physician scientists. Many gastroenterologists spend much of their time doing lucrative endoscopy, and unlike some other specialties, much of the work is performed by the physician and not by allied health personnel. The allure of higher incomes and

\footnotetext{
${ }^{1}$ Institute of Nutrition, Metabolism and Diabetes, Canadian Institutes of Health Research, Simon Fraser University, Burnaby, British Columbia; ${ }^{2}$ London Health Sciences Centre, London, Ontario

Correspondence and reprints: Dr Diane Finegood, Institute of Nutrition, Metabolism and Diabetes, Canadian Institutes of Health Research, Simon Fraser University, 8888 University Drive, West Mall Centre 2805, Burnaby, British Columbia V5A 1S6. Telephone 604-268-6707, fax 604-291-3055, e-mail finegood@sfu.ca
} 


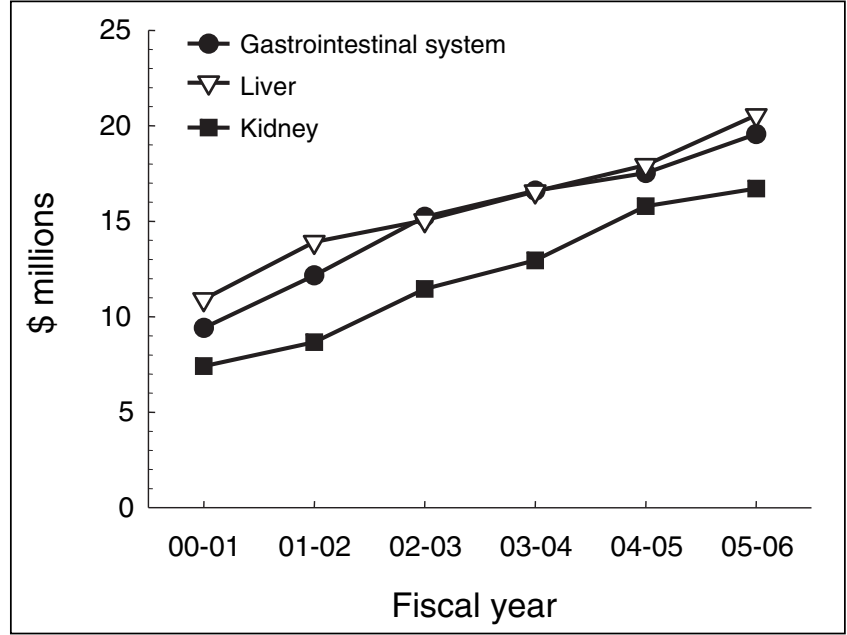

Figure 1) The Canadian Institutes of Health Research's funding for gastrointestinal system and liver grants and awards. Total funding for kidney-related research is shown for comparison. Key word searches of the Canadian Institutes of Health Research database were validated individually to verify relevance to the specific area

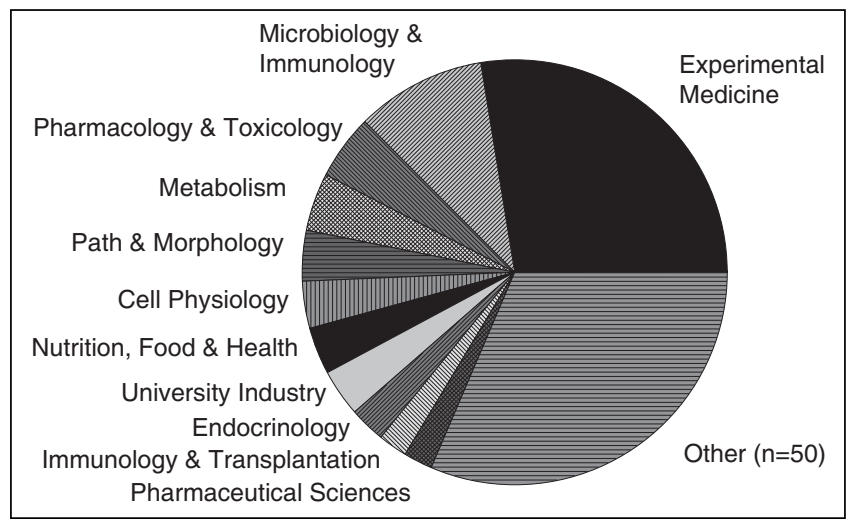

Figure 2) Proportion of the gastroenterology-funded grants from 2000 to 2006 reviewed by specific peer review panels. When liver grants were also considered, most of the top 10 review panels remained in the top 10, with the addition of Virus and Viral Pathogenesis. Path Pathology

greater financial stability has been a huge negative incentive. These issues likely cross many boundaries within the CIHR institute. Can you comment on future plans to encourage physicians to maintain involvement in Canadian medical research?

DF: Clinical research and support for research training for clinicians was identified as an early cross-cutting priority for the CIHR and its associated institutes. New opportunities for training support have been provided over the past years but the budget available for this priority has not grown as quickly as many of us would have liked. Our ability to grow support for clinician scientists will depend on growth in the CIHR's budget and its increase relative to pressure on other competitions including the large, open operating grant competitions.

Despite perceptions, the CIHR is funding more trainee and new investigator awards for GI researchers compared with kidney researchers and the numbers are growing, not shrinking (Figure 4). Many of these trainees are supported through

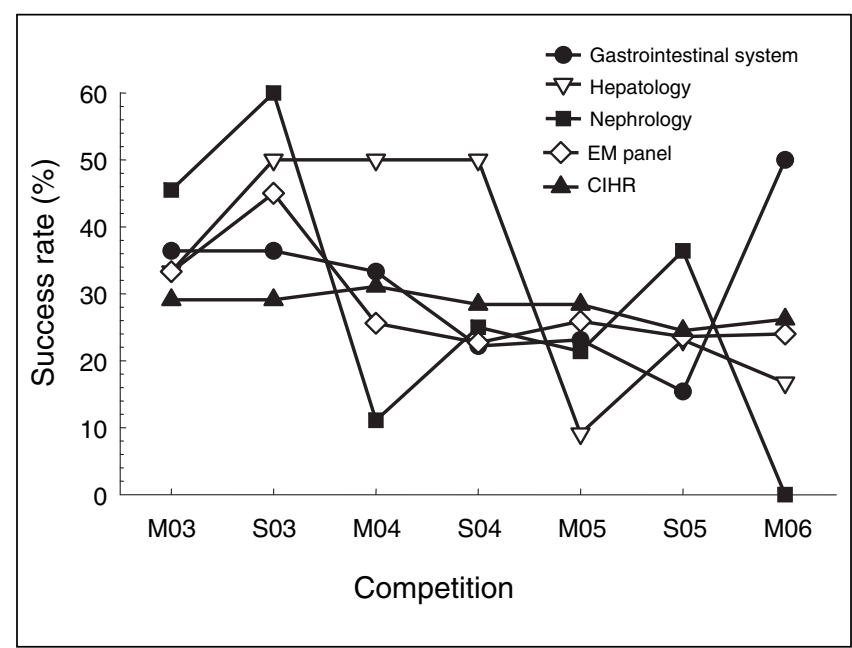

Figure 3) Success rate for grants in the major areas covered by the Experimental Medicine (EM) peer review panel over the past seven open operating grants competitions. CIHR Canadian Institutes of Health Research

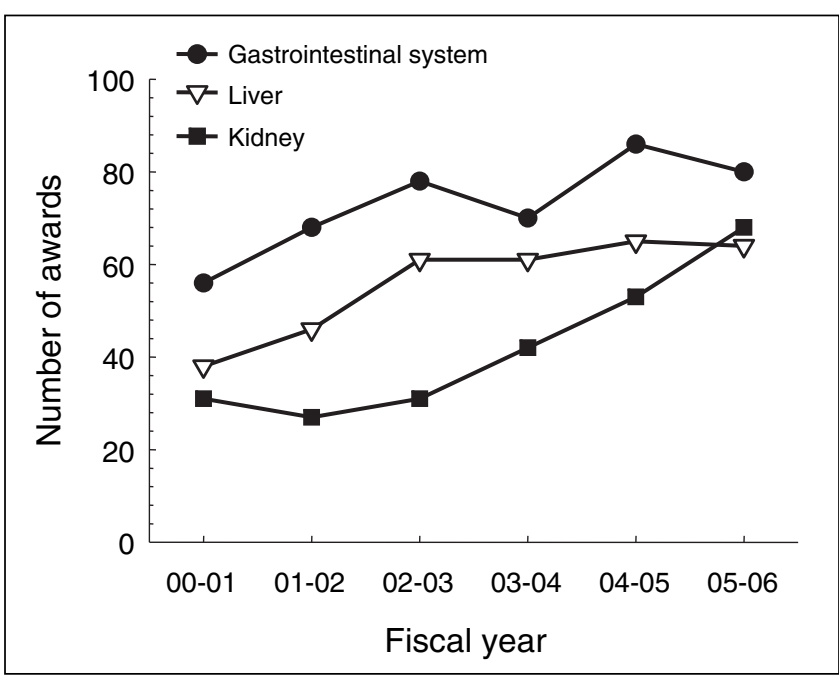

Figure 4) Number of awards (studentships, fellowships and investigator) supported by the Canadian Institutes of Health Research

partnerships with GI stakeholders including the Canadian Association of Gastroenterology, the Canadian Digestive Health Foundation and the pharmaceutical industry. Approximately $60 \%$ of these salary awards went to individuals who indicated that they were doing primarily basic research, approximately $10 \%$ to individuals doing clinical research and less than $5 \%$ to investigators who considered their work health services and policy research, or population and public health research. The remaining grantees did not specify the research theme for their work.

I imagine the incentive issue is not a new problem. While I do not have any particular knowledge of what would provide a greater allure, it appears that many young people are seeking, and are excited by, multidisciplinary training opportunities. The kidney research community was also concerned about the number of students doing degrees and the number of fellows doing research. To remedy this situation, the Canadian Society 
of Nephrology and the Kidney Foundation of Canada developed the Kidney Research Scientist Core Education and National Training (KRESCENT) program (3). This multidisciplinary national program is drawing significant numbers of high quality applicants, providing a multidisciplinary curriculum and may provide some additional allure for trainees to become more involved in kidney research.

PA: The INMD has placed a major emphasis on obesity. Fatty liver is one of the most common conditions seen by a gastroenterologist. Is this an area of focus of the INMD? Can you comment on other GI/hepatology areas?

DF: In 2001, the INMD's advisory board identified obesity and health body weight as the institute's strategic priority. This decision was based on many factors including the fact that it is a relevant priority for almost all areas included in the INMD's mandate. Most of the research funding opportunities created as a result of this strategic priority have been wide open to applications in any area relevant to obesity, including fatty liver disease, although relatively few applications have been received or funded in this area. It is important to remember that the focus on obesity only affects the use of our strategic funds which constitute only $1 \%$ of the total CIHR grants and awards budget. The majority of funds are still disbursed through the open operating grants competition.

There have been strategic initiatives in partnership with Health Canada in the area of hepatitis for a number of years and funding in this area accounts for approximately one-half of all liver research funded by the CIHR.

The INMD's strategy has been to stay focused on obesity and on strategic partnerships outside of the obesity area. As a result, the INMD has supported innovative partnerships with a number of health charities including the Heart and Stroke Foundation of Canada, the Kidney Foundation of Canada and the Canadian Diabetes Association to provide funding for programs such as New Emerging Teams in Chronic Disease and the KRESCENT program. We welcome suggestions from the GI and liver research communities for innovative partnerships that will help advance priorities of this community.

PA: Some of our researchers will be working in intestinal physiology, immunology, viral infections and genetics, and it is difficult to be sure which CIHR institute is best suited for our projects.

DF: I think most researchers could identify at least two or more institutes with which they could have an affiliation and I can see no reason for not developing these multiple linkages. All institutes welcome the input and participation of the research community in their various activities and a researcher may find value in participating in the activities of multiple institutes. The institute affiliation you indicate on your application when applying to the open operating grants competition is used for statistical and reporting purposes, and for priority announcement opportunities.

PA: The National Institutes of Health's funding system provides for much more investigator salary support and overhead costs. Do you see the CIHR moving more in this direction or is the CIHR budget the rate-limiting step?

DF: If the bulk of your funds go out the door in the form of grants then the budget is always a rate-limiting step. The challenge is to decide how to divide up the pie between the overwhelming number of highly fundable applications to the open competition, the types of support needed to properly operate the research engine and between the thematic priorities of the CIHR and its institutes. The issue of salary support has been discussed at length over the past several years in a committee struck to consider the issue, at the Research Planning and Priorities Committee of the CIHR, and the Governing Council. There are many arguments for and against the CIHR providing more investigator salary support but, at present, given our budget limitations, it seems unlikely that we will be able to reinstate the Investigator and Senior Investigator Awards program. Overhead costs are currently being paid directly to institutions and it is unlikely that this situation will change in the near future.

PA: Can you contrast and compare the CIHR system before and after the separation into these institutes?

DF: The establishment of the CIHR has led to a doubling of our grants and awards budget over the past six years. While the mandate for the CIHR has expanded to include health services and policy research, and population and public health research, very little of the GI funding goes into these areas as of yet. By covering all areas of health research from basic science to population health, and by focusing some initiatives on multidisciplinary teams, the CIHR has helped to create a more collaborative environment.

The creation of 13 institutes with Scientific Directors and their staff and Institute Advisory Boards has meant that the research community, as well as other stakeholders, have many more points of entry, many more opportunities to provide input and real mechanisms to help shape the strategic priorities of the organization. While the open operating grants competitions commit the majority of the CIHR's funding, the institutes are able to help advance priorities within the areas of their mandates.

PA: What is the best strategy for keeping our younger trainees interested in research-oriented careers?

DF: Given the current mismatch between the number of highly ranked grants and the CIHR budget, it is difficult across all areas of research to get trainees interested in researchoriented careers. It appears that what trainees are looking for may be changing. As noted earlier, the kidney research community seems to be having excellent success in attracting highquality applicants with their multidisciplinary KRESCENT program. Other training programs such as the INMD-funded program in digestive diseases at Queen's University (Kingston, Ontario) is also providing an environment that trainees seem to really enjoy.

\section{REFERENCES}

1. The Canadian Institutes of Health Research. Year 5 - international review panel report, 2000-2005. <http://www.cihr-irsc.gc.ca/ e/31464.html> (Version current at January 2, 2007).

2. The Canadian Institutes of Health Research. 37th meeting of the standing committee for oversight of grants and awards competitions. <http://www.cihr-irsc.gc.ca/e/31490.html> (Version current at January 2, 2007).

3. The Canadian Institutes of Health Research. Kidney researchers create unique training ground. <http://www.cihr-irsc.gc.ca/e/29102. html\#Kidney> (Version current at January 2, 2007). 


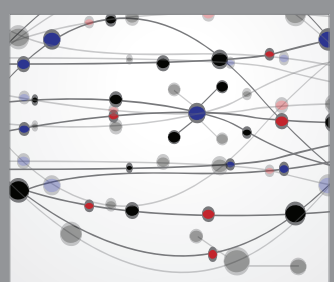

The Scientific World Journal
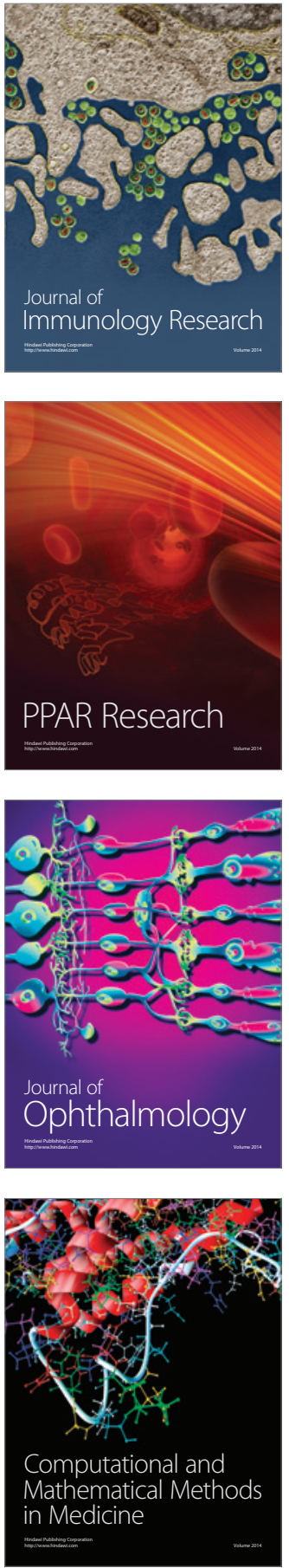

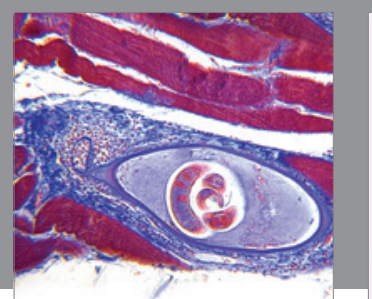

Gastroenterology Research and Practice

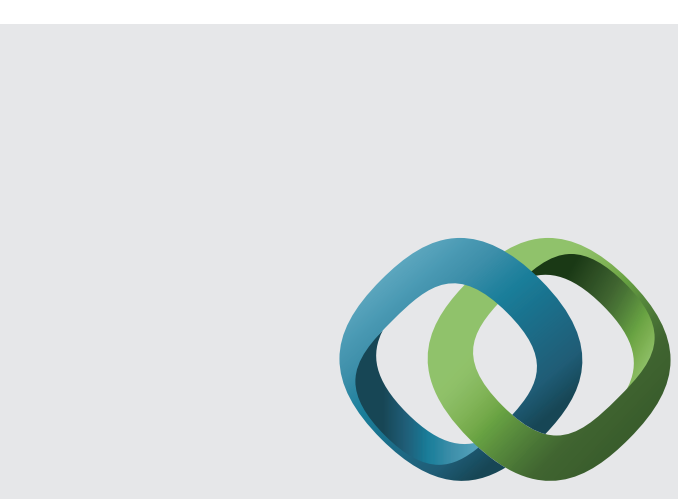

\section{Hindawi}

Submit your manuscripts at

http://www.hindawi.com
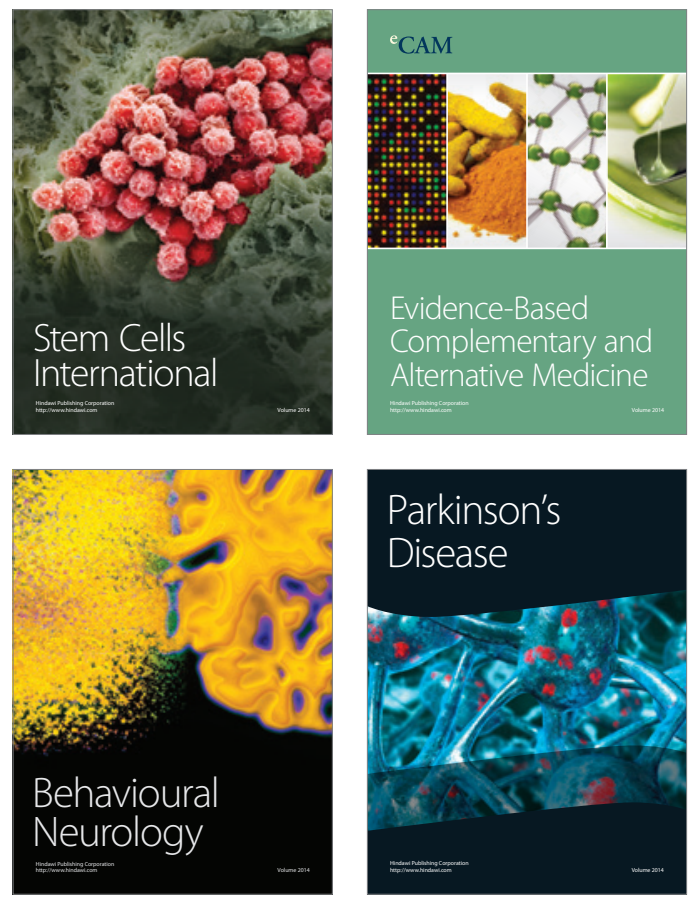
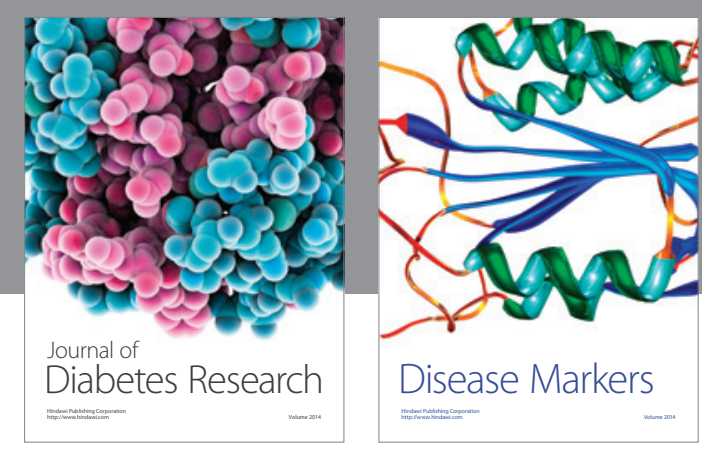

Disease Markers
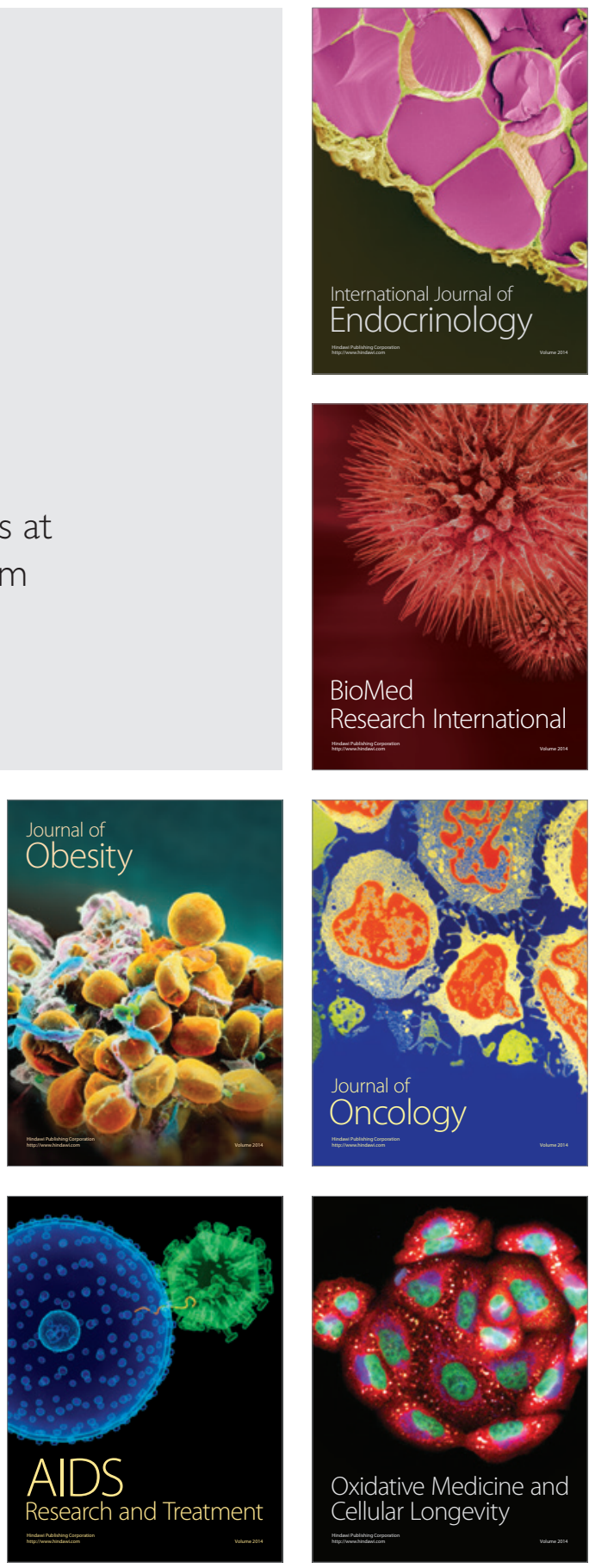